\title{
ANÁLISE DA ESCRITA DE UMA CRIANÇA COM HIPOMELANOSE DE ITO
}

\author{
Giselle Massi \\ Vera Lúcia Anunciação Costa \\ Ana Paula Santana \\ Ana Paula Berberian ${ }^{\infty}$ \\ Ana Cristina Guarinello \\ Rita de Cássia Tonochi ${ }^{\mathbb{E}}$ \\ Liziane Ghislandi ${ }^{\circledR}$
}

RESUMO. A hipomelanose de Ito caracteriza-se por manchas hipossegmentadas decorrentes de uma rara alteração na mielinização que pode ocasionar seqüelas neurológicas como déficit cognitivo, macrocelafia e epilepsia. O objetivo deste trabalho é analisar as características da linguagem escrita de um sujeito portador dessa alteração. Para tanto, nosso estudo se pauta em uma abordagem que toma a linguagem como atividade constitutiva. O resultado de nossas análises demonstrou que a aquisição da escrita do sujeito dessa pesquisa coincide com o processo previsível de desenvolvimento da linguagem, apesar dos déficits neurológicos que ele apresenta.

Palavras-chave: hipomelanose de Ito, linguagem, escrita.

\section{ANALYSIS OF WRITING OF A CHILD WITH ITO'S HYPOMELANOSIS}

\begin{abstract}
Ito's hypomelanosis is characterized by hyposegmental spots caused by a rare alteration in the melanization that may cause neurological sequences such as cognitive deficiency, macrocephaly and epilepsy. Current analysis bases itself on the approach that considers language as a constitutive activity. Results show that the acquisition of the written language of the subject in current research coincides with the predictable development of the language process in spite of its neurological deficiencies.
\end{abstract}

Key words: Ito's hypomelanosis, language, written language.

\section{ANÁLISIS DE LA ESCRITURA DE UN NIÑO CON HIPOMELANOSE DE ITO}

RESUMEN. La hipomelanosis de Ito se caracteriza por manchas hipo-segmentadas, decurrentes de una rara alteración que puede ocasionar secuelas neurológicas como el déficit cognitivo, macrocefalia y epilepsia. El objetivo de ese trabajo es analizar las características del lenguaje escrito de un sujeto portador de esa alteración. Para eso, nuestro estudio se orienta en un abordaje que toma el lenguaje como actividad constitutiva. El resultado de nuestros análisis ha demostrado que la adquisición de la escritura del sujeto de esa investigación coincide con el proceso previsible de desarrollo del lenguaje, a pesar de los déficits neurológicos que él presenta.

Palabras-clave: hipomelanosis de Ito, lenguaje, escritura.

* Doutora em Lingüística. Professora do Curso de Fonoaudiologia e do Programa de Pós-graduação em Distúrbios da Comunicação da Universidade Tuiuti do Paraná.

\# Doutora em Lingüística. Professora no Setor de Educação da Universidade Federal do Paraná.

Il Doutora em Linguística. Professora do Curso de Fonoaudiologia e do Programa de Pós-graduação em Distúrbios da Comunicação da Universidade Tuiuti do Paraná.

æ Doutora em História. Professora do Curso de Fonoaudiologia e do Programa de Pós-graduação em Distúrbios da Comunicação da Universidade Tuiuti do Paraná.

Æ Mestre em Distúrbios da Comunicação. 
A hipomelanose de Ito é uma hipocromia segmentar caracterizada por manchas cutâneas, decorrentes de uma rara alteração na mielinização e pode estar associada a manifestações neurológicas, musculoesqueléticas, oftalmológicas, malformações cardíacas, orais, genitais e urológicas. Apresentandose no nascimento ou nos primeiros anos de vida, anomalias provocadas por essa patologia podem comprometer o desenvolvimento e a maturação do indivíduo, conforme apontam Almeida et al. (2001), Curatola e Massimo (2005).

Pesquisas referem que, em uma série de 34 casos, o retardo mental está presente em $64,7 \%$ dos sujeitos estudados, coincidindo, segundo Rittey (2003) e Vasconcelos (2004), com macrocefalias e crises epiléticas. Outras alterações lingüístico-cognitivas mais freqüentes são: atrasos psicomotores e de linguagem, hiperatividade, déficit de atenção, sendo também encontrados casos de retardo mental associado a comportamentos autistas. A principal complicação neurológica encontrada tem sido atraso psicomotor ou mental. De 14 pacientes estudados, apenas um tinha um nível cognitivo considerado normal, de acordo com Gómez-Lado et al. (2004).

A literatura sobre o assunto apresenta-se escassa com relação à análise da linguagem escrita de sujeitos com hipomelanose de Ito; e o desempenho escolar, no caso desses sujeitos, merece uma análise cuidadosa, uma vez que as potencialidades de tais crianças tendem a ser desconsideradas e ressaltadas suas possíveis limitações, conforme apontam Massi e Anunciação (2002). Tal situação torna-se ainda mais crítica tendo-se em vista a carência de estudos que buscam analisar o desenvolvimento lingüístico, cognitivo e emocional dessa população.

Neste trabalho pretendemos analisar textos escritos elaborados por uma criança portadora de hipomelanose de Ito, visando compreender as implicações dessa enfermidade no desenvolvimento da escrita. Para tanto, privilegiamos uma perspectiva sociointeracionista, representada por Bakhtin (1992), a qual aponta que é por meio da relação com o outro que o aprendiz se subjetiva e se relaciona com a escrita como um objeto de conhecimento. Nessa direção, tomamos a linguagem, segundo Franchi (1992), como atividade constitutiva e, assim, adotamos estudos que distinguem três tipos de operações relacionadas às ações que os sujeitos exercem com e sobre a linguagem: lingüística, metalingüística e epilingüística. Conforme proposto por Geraldi (1995), a primeira, vinculada à operação lingüística, diz respeito ao sentido do conteúdo tratado entre os interlocutores; a segunda volta-se para a classificação e conceituação da linguagem, sem se preocupar com os processos interlocutivos; e a terceira, a atividade epilingüística, está relacionada às reflexões sobre os recursos expressivos usados no texto.

Além disso, buscamos embasamento na lingüística textual que, conforme Koch (2003), delimita o texto como atividade dialógica, como um trabalho de interação entre sujeitos sociais, contemporâneos ou não, co-presentes ou não, mas em diálogo constante. Nesse sentido, concebemos o texto segundo Koch e Travaglia (1996): como uma produção escrita que em um dado processo de interação forma um contínuo comunicativo, independentemente de sua extensão.

\section{MÉTODO}

Para cumprir o objetivo proposto, analisamos o caso de um menino de 9 anos, representado pela letra W., que, conforme diagnóstico neurológico, tem hipomelanose de Ito, uma vez que apresentava hipocromia segmentar. De início convém observar que, pelo fato de analisar um caso clínico, a pesquisa foi submetida à aprovação do Comitê de Ética em Pesquisas em Humanos da Universidade Tuiuti do Paraná, de acordo com ofício CEP-UTP nº. 80/2004. Segundo o diagnóstico neurológico acerca do caso, a hipomelanose de Ito afeta várias áreas cerebrais, alterando o raciocínio, a memória visual, o processamento do pensamento e outras capacidades humanas. Além disso, pelo fato de a criança em questão não contar com comprometimentos musculoesqueléticos e apresentar dificuldades de leitura e escrita, o neurologista a encaminhou para uma avaliação mais específica no Serviço de Avaliação e Múltiplo Atendimento da Fundação Ecumênica de Proteção ao Excepcional. De acordo com o relatório avaliativo realizado por esse Serviço, em novembro de 1999, W. apresentava normal desenvolvimento motor e da fala, porém com alterações cognitivas e no desenvolvimento da leitura e da escrita.

Quanto ao desempenho escolar, esse mesmo relatório apontava W. como um sujeito que demonstrava defasagens quando comparado com outras crianças, pois, embora estivesse cursando a segunda série do ensino fundamental, apresentava nível de primeira. Em função de tal relatório, W. iniciou atendimento fonoaudiológico para superação de suas dificuldades com a linguagem escrita.

Ainda sobre a questão escolar, convém esclarecer que a metodologia desenvolvida na escola freqüentada por W. seguia critérios tradicionais, os quais se 
distanciavam de práticas de letramento e pautavam-se na grafia, codificação/decodificação de letras, sílabas e, no máximo, de frases fragmentadas afastadas de um contexto significativo. Em outras palavras, o trabalho com a escrita que W. estava desenvolvendo na escola não era baseado em práticas efetivamente sociais de leitura e escrita, capazes de tomar o sujeito-aprendiz como participante ativo no processo de ensinoaprendizagem. Tanto que os cadernos escolares dessa criança eram repletos de tarefas mecânicas fundamentadas em exercícios que privilegiavam cópias de letras, números e palavras isoladas.

Quanto aos procedimentos avaliativos e terapêuticos fonoaudiológicos relacionados à escrita, foram utilizados princípios norteadores adotados pela Clínica de Fonoaudiologia da Universidade Tuiuti do Paraná, elaborados pelos pesquisadores que compõem o Núcleo de Estudos: Fonoaudiologia e Linguagem Escrita, vinculado ao Programa de Pós-graduação em Distúrbios da Comunicação, dessa mesma Universidade. Tais princípios fundamentam-se em uma perspectiva social e discursiva de linguagem, conforme anunciam Berberian (2003); Guarinello \& Pan (2001); Perrota, Massini e Mãrtz (2004).

Os dados de escrita analisados foram registrados por escrito por uma das pesquisadoras, durante as dez sessões fonoaudiológicas realizadas com a própria criança. Assim, levando-se em conta o diagnóstico médico e a avaliação do Serviço de Proteção ao Excepcional, já comentados anteriormente, foram selecionadas quatro produções escritas elaboradas por W. no decorrer das dez sessões fonoaudiológicas individuais, as quais foram desenvolvidas a partir de atividades significativas de leitura e escrita. Durante essas atividades foram coletados e registrados episódios referentes às atitudes evidenciadas por W. no momento em que ele produzia os seus textos. As práticas significativas com a linguagem escrita desenvolvidas durante os atendimentos fonoaudiológicos, diferentemente das propostas escolares, estiveram voltadas para atividades dialógicas que ressaltaram o encontro da palavra de W. com o outro. Destarte, distantes de tarefas decodificatórias, tais atendimentos estiveram envolvidos com a produção de textos efetivamente escritos por W. para um interlocutor definido, tais como pequenos bilhetes, relatos de experiências pessoais, narrativas de ficção, conforme apresentado e discutido na sequiência.

\section{ANÁLISE DOS DADOS DA ESCRITA}

No primeiro encontro observamos que, embora dispersivo, W. parecia não ter dificuldades em relação à oralidade em situação conversacional, ao contrário do que acontecia em circunstâncias de leitura. Solicitado a ler um livro, somente soletrou algumas palavras com ajuda da fonoaudióloga. Em seguida, recusou-se a prosseguir, tomando a posição apenas de ouvinte. Entendemos que esse fato pode estar relacionado às dificuldades que ele apresentou durante $\mathrm{o}$ ato de leitura. Como sua postura diante do texto era decodificatória, seguindo a metodologia adotada em sua escola, W. identificava as letras e tentava relacioná-las, mas não conseguia dar significado ao que lia; ou seja, aspectos formais relacionados ao texto escrito sobrepunham-se ao conteúdo, comprometendo a interpretação e afastando a criança da leitura propriamente dita.

Com relação à escrita, constatamos falta de autonomia para a elaboração de textos. Nesse sentido, com o intuito de favorecer a produção de textos escritos, foram realizadas várias atividades com a oralidade e a leitura. Entretanto, inicialmente a criança manteve-se dependente da interlocutora adulta, só conseguindo escrever a partir de indagações a propósito da ortografia e da segmentação das palavras e sem nenhuma preocupação com questões textuais, revelando a concepção de escrita que provavelmente a escola havia lhe transmitido, isto é, uma concepção que entende a escrita como mero código encerrado em si mesmo.

Não obstante, as excessivas perguntas sobre a forma não isentaram seus pequenos textos da ocorrência de hipossegmentações, trocas/ supressões de letras e supressões de palavras, mostrando a capacidade de reflexão sobre a linguagem. Ao longo dos encontros com W., foi possível perceber que essas reflexões foram modificando sua escrita.

Antes de analisar a escrita de W., cabe salientar que, além de conhecer todo o alfabeto, a criança praticamente não apresentava problemas em relação à escrita de palavras isoladas. Em um de nossos encontros, solicitado a mostrar o que aprendia na escola, W. escreveu todas as letras do alfabeto e uma seqüência de oito palavras, das quais sete estavam de acordo com a convenção ortográfica, dentro dos moldes do tradicional ditado escolar, conforme podemos verificar na transcrição que apresentamos a seguir:

$$
\begin{aligned}
& \text { A-B-C-D-E-F-G-H-I-F-G-H-I-J-L-M-NOPQN } \\
& \text { S-T-U-V-X-Z-K-W-Y- } \\
& \text { GATO-RTO-DIA-SAPATO } \\
& \text { DADO-BOLA-FADA-FOCA }
\end{aligned}
$$

Passemos ao primeiro texto apresentado por W.: 
Texto 1 -

\section{Panoeu é aro uviboene Willian}

Papai Noel eu quero um videogame.

Tendo em vista a época de Natal, conversamos sobre o presente que W. gostaria de ganhar. Depois, sugerimos a ele que escrevesse um bilhete para o Papai Noel, expondo o seu desejo. W. mostrou-se ansioso, repetindo, por várias vezes, que não sabia fazer o bilhete. Pedimos, então, que ele produzisse oralmente o seu bilhete, o qual foi construído sem dificuldade. Na seqüência, ditamos para W. a sua própria produção oral e ele começou a escrever, perguntando seguidamente: "eu tô fazendo certo? Aqui é junto ou separado?".

Mostrando-se amedrontado, W. só conseguiu escrever quando a fonoaudióloga ditava o texto. A necessidade de que o outro lhe ditasse pode ser explicada pela preocupação de W. com questões gráficas. Assim como acontecia na sua leitura, o seu envolvimento com a forma, no momento da escrita do texto, era tanto que ele parecia esquecer-se do conteúdo. Por isso, era necessário que repetíssemos o discurso que ele próprio havia produzido oralmente.

Com relação aos aspectos gráficos e convencionais da escrita, é possível perceber que W. ainda toma a fala como referência para a escrita pela constatação das hipossegmentações "Panoeu" (Papai Noel) e "uviboene" (um videogame) e que ainda não relaciona certas letras a determinados fonemas. $\mathrm{Ou}$ seja, ele ainda se pauta no contínuo da fala em alguns momentos, mas tem problemas para transcrever letras correspondentes a certos sons individuais.

O fato de acentuar "eu", representado por "é", pode ser atribuído à tonicidade da primeira sílaba da palavra imediatamente seguinte, "quero", grafada "aro". A supressão do dígrafo "qu" pode ter ocorrido pelo fato de o fonema $[\mathrm{k}]$ ser transcrito, na escrita ortográfica do português, tanto por "c" quanto por " $\mathrm{k}$ " ou "qu", dando margem a dúvidas e inseguranças e levando a criança a optar pela não-representação do fonema em seu texto. Além disso, "que" constitui uma sílaba complexa (consoante-vogal-vogal) e as crianças tendem a produzir a escrita inicial de acordo com forma canônica da língua (consoante-vogal), conforme Abaurre \& Silva (1993). Ainda, em relação a esse item lexical, é conveniente lembrar que a troca do "e" pelo " $a$ " pode ter acontecido em razão da proximidade fonética entre a vogal central baixa e a vogal anterior média.
A criança, além disso, não escreve a segunda sílaba da palavra "papai" porque talvez já tenha percebido que, em nossa língua, as palavras não repetem, comumente, as mesmas estruturas silábicas. Por isso, pode ter optado pela forma que lhe parece menos estranha.

A troca de "l" por " $u$ ", em "Noel" se dá porque, nesses contextos - em trava de sílaba ou final de palavra -, o "l" se conserva apenas na escrita do português do Brasil, sendo uma mudança lingüística implementada na fala da grande maioria dos falantes da língua, segundo Cagliari (1998).

Constatamos também a supressão de " $\mathrm{m}$ " em "um", fato corriqueiro na escrita inicial, provavelmente pelas diferentes maneiras de representação da nasalidade na escrita ("m", "n" e “ "), bem como porque a criança deve ter percebido que, efetivamente, o que temos na fala é uma vogal nasalizada e não uma consoante nasal. A troca de " $m$ " por " $n$ " em "videogame" pode ter ocorrido pelos mesmos motivos já descritos anteriormente.

Finalmente, a troca de "d" por " $b$ " em "videogame" pode ser explicada pelo fato de [d] e [b] serem, ambos, fonemas oclusivos e W., intuitivamente, deve ter considerado esse traço articulatório no momento em que estava escrevendo.

A análise desse primeiro texto nos leva a perceber que W. não domina a convenção ortográfica; entretanto, não podemos tomar seus "erros" como sintomas de um déficit cognitivo imutável. Antes disso, os "erros" de W. devem ser encarados como parte de uma situação transitória, resultante de reflexões lançadas sobre a língua, conforme anunciado por Massi (2001). Isso parece tanto mais evidente se compararmos a escrita de W. ao grafar, em um primeiro momento, letras e palavras isoladas e, depois, em situações significativas.

No primeiro caso, ao escrever letras e palavras soltas, ele nada perguntou, realizou com destreza a tarefa artificializada, porque automática e bastante trabalhada na escola que freqüentava. $\mathrm{Na}$ seqüência, em situações significativas, viu-se obrigado a refletir sobre a escrita. As dúvidas, inseguranças e "erros" passaram a acontecer justamente a partir de suas reflexões.

\section{Texto 2 -}

et é arro do Willian. Ele foi para praia iaora et ido para casa. Et carro é siza mara fode e foi fadicado e 1991.

Este é o carro do Willian. Ele foi para praia e agora está indo para casa. Este carro é cinza marca ford e foi fabricado em 1991. 
Por iniciativa própria, W. desenhou um carro. Aproveitando a situação, passamos a fazer perguntas, às quais ele respondeu com desenvoltura. Entre perguntas e respostas, em uma construção conjunta, produzimos oralmente o texto. Pedimos então a W. que elaborasse uma produção escrita sobre o seu desenho, para que outras crianças freqüentadoras da Clínica de Fonoaudiologia pudessem ler seu texto, e percebemos que sua postura diante da escrita mudava: sua excessiva preocupação com questões gráficas parecia diminuir.

Percebendo que podia manipular o objeto escrito, W. parecia estar entendendo que estabelecíamos uma relação de troca, na qual ele escrevia não para ser testado ou corrigido, mas para usar a linguagem de maneira efetiva.

Além disso, W. demonstrava ter noção dos mecanismos envolvidos em uma produção textual. Utilizando-se desses mecanismos, ele construiu uma unidade significativa, criando características descritivas para o carro desenhado - cor, marca, ano de fabricação, esclarecendo, inclusive, de quem era o objeto descrito: "Este carro é do Willian... Este carro é cinza marca ford e foi fabricado em 1991". Mantendo coerência em seu texto, W. criou uma situação, envolvendo o objeto descrito em um evento/ação: "Ele foi para praia e agora está indo para casa”.

\section{Texto 3 -}

$\begin{aligned} & \text { eu fisaniversario e gamhei uma bola e um } \\ & \text { carrinho }\end{aligned}$
Willian

Eu fiz aniversário e ganhei uma bola e um carrinho Willian

No dia em que W. produziu esse texto, chegou entusiasmado à sala de terapia. Contou sobre o seu aniversário e sobre a festa que sua mãe havia organizado. Ele falou livremente sobre tal evento, e depois de se envolver com o seu discurso a fonoaudióloga solicitou o registro escrito do seu relato oral.

Apesar de o texto escrito ter sido elaborado de forma resumida, chamou-nos a atenção a tranquiilidade de W. ao construí-lo. Sem demonstrar medo ou insegurança, atitudes corriqueiras nas suas primeiras produções, ele construiu um breve relato sobre o seu aniversário. Utilizando-se de verbos de ação no tempo perfeito - fiz e ganhei -, encadeou dois eventos - fazer aniversário e ganhar presentes - a partir de uma relação de dependência entre ambos.
Destarte, W. mostrou que tem condições de recuperar por meio da linguagem - oral e escrita experiências pessoais vivenciadas por ele em momentos anteriores ao da enunciação. Ele recontou eventos/ações, relatando fatos por ele vivenciados.

Nesse sentido, cabe ressaltar que, como qualquer outra criança em fase de apropriação da linguagem, W. apresentou instabilidades que revelam as hipóteses usadas para construir a escrita. É exatamente por refletir e criar hipóteses para resolver os problemas encontrados no momento dessa construção que W. escreveu, por exemplo, "fisaniversario". Provavelmente, ainda pautado no contínuo da fala, faz essa hipossegmentação. Por outro lado, com relação à textualidade, no relato analisado, W. mais uma vez demonstrou que pode construir um todo significativo. Seu texto apresenta-se coerente, formando uma unidade de sentido.

\section{CONSIDERAÇÕES FINAIS}

Pela análise dos dados, podemos entender que a interferência da fonoaudióloga atua positivamente na escrita de W. Ressaltamos, especificamente, as atividades epilingüísticas realizadas pelo sujeito, as quais permitiram que sua escrita sofresse modificações em direção à convenção ortográfica.

Esse fato nos leva a considerar duas questões fundamentais. A primeira diz respeito ao produto versus processo. A descrição de produtos lingüísticos estáticos, elaborados em situações de testagem, desconsidera a atividade do sujeito e da linguagem, pois se volta para "o que" a criança é capaz de produzir lingüisticamente, e não para a explicação de "como" ela o faz. Em direção oposta, ao adotarmos uma visão processual, voltada para o processo de apropriação da escrita, pudemos compreender e participar do desenvolvimento lingüístico de $\mathrm{W}$., reconstruindo o caminho que ele percorre para apreender a escrita.

A segunda questão refere-se ao fato de que, nesse caminho, os "erros" não são desconsiderados nem tomados como incapacidades ou anormalidades, e sim, entendidos como mecanismos - reflexões e hipóteses que constituem o processo de apropriação do objeto escrito. Dessa forma, os "erros" passam a iluminar o percurso trilhado pela criança.

No início de nosso trabalho com W. percebemos que, por interferência da escola, ele se preocupava apenas com aspectos formais da leitura e da escrita. Essa preocupação o impedia de perceber que para escrever é necessário um motivo, um desejo, uma necessidade de comunicar-se. 
Na seqüência, discutindo o conteúdo de leituras e escrevendo textos significativos, ele passou a refletir sobre a escrita. Em função dessas reflexões, acompanhamos os recursos usados por W. para construir esse objeto: tomava o contínuo da fala como referência, trocava e suprimia letras, utilizava-se de transcrição fonética, fatos previsíveis na escrita inicial de crianças que têm a oportunidade de produzir textos espontâneos, segundo apontado por vários pesquisadores brasileiros, como Abaurre \& Silva (1993); Cagliari (1998); Massi \& Berberian (2005).

Esses fatos, que nada têm de anormal, tendem a desaparecer à medida que a criança, em conjunto com o adulto, atua sobre a modalidade escrita da linguagem. Ao compararmos o texto 1 com o texto 3 percebemos que, em conjunto com a fonoaudióloga, W., no decorrer de dez encontros, apresentou modificações relevantes na forma de sua escrita.

De um ponto de vista textual, ele demonstrou que tinha condições de integrar diferentes aspectos do funcionamento da língua na interação comunicativa: fazendo uso de recursos capazes de encadear coerentemente as partes do seu texto, desenvolvendo pequenos relatos, respeitando o tema proposto.

Assim, ressaltamos a necessidade de entender que cada sujeito, de alguma maneira, é único, e que sua singularidade, como bem aponta Massi (2004), deve ser considerada nos estudos preocupados com a apropriação da escrita, em detrimento de uma visão que desconsidera o sujeito e ressalta as características da patologia da qual ele é portador.

Sem esse tipo de análise, corremos o risco de fazer comparações simplistas que desconsideram o percurso variável e singular que cada criança faz no processo de apropriação da escrita. Ao contrário das simples comparações, a análise desse processo nos levou a acompanhar as modificações que foram ocorrendo na escrita de W., e essas modificações nos revelam que o sujeito deve ser comparado somente com ele mesmo.

A partir do estudo realizado consideramos que, longe de comparações equivocadas e de avaliações estanques, W. mostrou que tem condições de adquirir a escrita, embora seja portador de hipomelanose de Ito, uma doença que ocasiona defasagens cognitivas.

\section{REFERÊNCIAS}

Abaurre, M. B. M. \& Silva, A. (1993). O desenvolvimento de critérios de segmentação na escrita. Temas em Psicologia, 1, 89-102.
Almeida, A. S., Cechin, W. E., Ferraz, J., Rodriguez, R., Moro, J., Jorge, R. \& Rosa, L. C. (2001). Hipomelanose de Ito: relato de um caso. Jornal de Pediatria, 77(1), 59-62.

Bakhtin, M. (1992). Estética da criação verbal. São Paulo: Martins Fontes.

Berberian, A. P. (2003). Princípios norteadores da avaliação clínica fonoaudiológica de crianças consideradas portadoras de distúrbios de leitura e escrita. Em A. P. Berberian, G. A. Massi \& A. C. Guarinello (Orgs.), Linguagem escrita: referenciais para a clínica fonoaudiológica (pp. 11-38). São Paulo: Plexus.

Cagliari, L. C. (1998). Alfabetizando sem o bá - bé - bi - bó - bu. São Paulo: Scipione.

Curatola, R. \& Massimo, J. (2005). Hipomelanosis de Ito. Recuperado em 02 de maio de 2006, de http://www.bireme.br/egr-bm/PAH2.

Franchi, C. (1992). Linguagem: atividade constitutiva. Cadernos de Estudos Lingüísticos, 22, 9-39.

Geraldi, J. W. (1995). Portos de passagem. São Paulo: Martins Fontes.

Gómez-Lado, C., Eirís-Puñal, Blanco-Barca, J., Del Rìo-Latorre, E., Fernàndez-Redondo, V. \& Castro-Gago, M. (2004) Hipomelanose de Ito: Un síndrome neurocutáneo heterogéneo y posiblemente infradiagnosticado. Revista de Neurologia, 38(3), 223-228.

Guarinello, A. C. \& Pan. M. A. G. S. (2001). As contribuições da lingüística textual para avaliação da linguagem escrita na infância. Revista Pró-Fono, 13(2), 181-189.

Koch, I. V. \& Travaglia, L. C. (1996). A coerência textual. São Paulo: Contexto.

Koch, I. V. (2003). Desvendando os segredos do texto. São Paulo: Cortez.

Massi, G. A. A. (2001). A escrita de um aluno: uma análise lingüístico-textual. Revista Pró-Fono, 13(2), 190-194.

Massi, G. A. A. (2004). Dislexia ou processo de aquisição da escrita? Revista dos Distúrbios da Comunicação, 16(3), 355 - 369.

Massi, G. A. A. \& Anunciação V. L. (2002). Considerações linguísticas sobre um caso de hipomelanose de Ito. Revista Fragmenta, 17, 153-163.

Massi, G. A. A. \& Berberian, A. P. (2005). A clínica fonoaudiológica voltada aos chamados distúrbios de leitura e escrita: uma abordagem constitutiva da linguagem. Revista da Sociedade Brasileira de Fonoaudiologia, 10(1), 43 - 52.

Perrota, C., Massini, L. \& Mãrtz, M. L. W. (2004). O trabalho terapêutico fonoaudiológico com a linguagem escrita: considerações sobre a visitação a gêneros discursivos. Revista de Distúrbios da Comunicação, 16(6), 181-194.

Rittey, C. D. (2003). Learning difficulties: What the neurologist needs to know. Journal Neurol Neurosurg Psychiatry, 74, 30-36.

Vasconcelos, M. M. (2004). Retardo mental. Jornal de Pediatria, $80(2), 71-82$.

Recebido em 08/08/06

Aceito em 14/05/07

Endereço para correspondência: Giselle Massi. Rua Monsenhor Manoel Vicente, 532, ap. 61, Água Verde, CEP 80620-230, Curitiba-PR.E-mail: giselle.massi@utp.br 